\title{
RESEÑAS BBLIOGRÁFICAS
}

\section{RESEÑA DE "EL RÉGIMEN FISCAL DE LOS PLANES DE PENSIONES EN FAVOR DE PERSONAS CON DISCAPACIDAD"}

\author{
(DE PABLO VARONA, C., ARANZADI, 2019)
}

\section{Carlos Cuervo Fernández}

Becario de colaboración

Universidad de Cantabria

cfc322@alumnos.unican.es ORCID 0000-0003-4767-3360

Recepción de trabajo: 11-06-2021 - Aceptación: 13-06-2021

Los planes de pensiones son un instrumento que, en su origen, y siendo los gobiernos conscientes de que el envejecimiento de la población desembocaría en la insostenibilidad de las prestaciones por jubilación, se gestaron con el objetivo de que los ciudadanos tuvieran incentivos en constituir un ahorro suficiente para que, una vez verificada la contingencia, pudieran obtener una prestación complementaria a la pública que les permitiera disfrutar de una renta mensual lo más próxima posible a la que generaban en el momento inmediatamente anterior a tal contingencia. Con este objetivo en mente, se diseñó un sistema financiero y actuarial de capitalización, cuyo principal atractivo era el diferimiento de la renta a través de la reducción en la base imponible general del total de las cantidades aportadas al plan en un determinado ejercicio, hasta un máximo. Es cierto que dichas cantidades serán computadas en la base imponible general cuando se obtengan en forma de renta, pero no lo es menos que, normalmente, las prestaciones por jubilación son inferiores a las que se obtienen por el trabajo durante la vida activa lo que, conjugado con la progresividad que caracteriza a la imposición directa, da como resultado un ahorro fiscal.

El régimen general, que es desgranado con la profundidad necesaria para transitar con facilidad a través de una sinuosa regulación, sirve como base al régimen especial de los planes de pensiones en favor de personas con discapacidad, cuya arquitectura se recoge en la Disposición adicional cuarta del Real Decreto Legislativo 1/2002, de 29 de noviembre, por el que se aprueba el texto refundido de la Ley de Regulación de los Planes y Fondos de Pensiones. El principio informador es ahora el de la protección patrimonial de las personas con discapacidad, y es esta una idea que el lector debe tener presente en todo momento, ya que no solo converge en una regulación financiera y fiscal orientada a fomentar el máximo ahorro posible que pueda cubrir las necesidades de la persona con discapacidad una vez que falten sus principales cuidadores, 
“EL RÉGIMEN FISCAL DE LOS PLANES DE PENSIONES EN FAVOR DE PERSONAS CON DISCAPACIDAD”

sino que se va a constituir en punto de referencia para la integración de las lagunas que surgen con el estudio de la normativa y en criterio hermenéutico fundamental a lo largo de la obra.

Esta idea que gobierna el régimen especial cristaliza en varias especialidades que, a priori, parecen un estímulo eficaz para constituir este tipo de instrumentos de protección patrimonial en favor de personas con discapacidad, y que se van a manifestar de forma más intensa en el régimen de las aportaciones y de las prestaciones. Así, el máximo total que se podrá aportar [y consecuentemente reducir de la base imponible general del aportante] anualmente al plan alcanza los 24.250€; mientras que el tope por cada aportante se fija en 10.000€. Además, las contribuciones o aportaciones ya no deberán realizarse únicamente por el promotor y los partícipes, sino que también los familiares de la persona con discapacidad hasta un determinado grado podrán aportar al plan. En el ámbito de la prestación se prevé un incentivo a la salida que abandona, al menos en parte, la idea del diferimiento de la imposición para declarar exentas, hasta un máximo, las prestaciones obtenidas en forma de renta.

Sin embargo, el autor identifica varias disfunciones que van a provocar que el instrumento no tenga toda la acogida entre la sociedad que sería deseable o que la protección de la que gozará el beneficiario del plan una vez verificada la contingencia no sea aquella que hubiera podido esperar. Centra especialmente la atención de la obra el copago al que deben hacer frente los usuarios del Sistema para la Autonomía y Atención a la Dependencia, que puede alcanzar el 90\% del coste del servicio. Para el cálculo del porcentaje se tiene en cuenta la capacidad económica del beneficiario, computándose a tal efecto las rentas obtenidas de los diferentes instrumentos de previsión social, gran parte de las cuales irán destinadas a sufragar ese copago. El resultado que ello genera se revela evidente: desincentiva las aportaciones de los beneficiarios y sus familias, que observan cómo sus esfuerzos económicos revierten a las arcas públicas para contribuir a un servicio al que la persona con discapacidad también tendría acceso si no dispusiera de aquellas rentas.

Pero hay más ejemplos. Si el fin del régimen especial es garantizar a las personas con discapacidad una protección económica suficiente cuando lleguen a necesitarlo, cabe preguntarse cuál es la ratio detrás de la norma que restringe el círculo de posibles aportantes al plan a personas unidas por parentesco con la persona con discapacidad en línea recta o colateral hasta el tercer grado [de afinidad, según la DGPFP], al cónyuge y a aquellos que le tuviesen a su cargo en régimen de tutela o acogimiento. El mismo interés en contribuir a la protección de estas personas podrían tenerlo la pareja de hecho, el primo o la abuela política y, sin embargo, no podrán realizar aportaciones. Tampoco se entiende bien la exclusión de los curadores, menos aun con la reciente entrada en vigor de la Ley 8/2021, de 2 de junio, por la que se reforma la legislación civil y procesal para el apoyo a las personas con discapacidad en el ejercicio de su actividad jurídica, que ha supuesto un cambio de paradigma en el tratamiento jurídico de la discapacidad en España. Convertida la curatela en la institución fundamental y principal en el apoyo a las personas con discapacidad, pocas dudas cabe albergar sobre la necesidad de incorporar a estas personas al elenco de las facultadas para realizar aportaciones a planes de pensiones en el régimen especial que venimos comentando. Ninguna mención hace la Ley al respecto, desaprovechando una valiosa oportunidad para dar solución a estos problemas. 
“EL RÉGIMEN FISCAL DE LOS PLANES DE PENSIONES EN FAVOR DE PERSONAS CON DISCAPACIDAD”

Desde la perspectiva de la protección a la persona con discapacidad tampoco se comprenden bien las razones que motivaron la eliminación de la reducción del $40 \%$ para el caso de que la prestación se recibiera en forma de capital. Por más que ello pudiera tener sentido en el régimen general, donde se pretende que la prestación funcione como complemento a la renta pública, en el caso de las personas con discapacidad ya hemos visto cómo no es este el objetivo perseguido. Es más, es precisamente en el supuesto de las personas con discapacidad donde más necesaria pudiera ser aquella reducción, ya que los elevados gastos que pueden llegar a afrontar, derivados de sus especiales necesidades, justifican la obtención de la prestación en forma de capital. Navarra, que cuenta con régimen foral propio, ha mantenido este beneficio.

Son muchas otras las cuestiones que son tratadas con rigor en la obra, pero no éste el lugar para referirse a todas ellas. Se trata de una monografía de imprescindible lectura para todos aquellos interesados en planificar la protección patrimonial de las personas con discapacidad que estén a su cargo -como la del mismo autor Los patrimonios protegidos de las personas con discapacidad. Régimen fiscal, Aranzadi, 2018, que aborda otra herramienta diseñada con el mismo objeto- y también para aquellos llamados a configurar los medios necesarios para que dicha protección pueda articularse de la forma más eficiente posible. A ello contribuye el autor con varias exhortaciones a reformar aquellos puntos que dificultan la consecución de los fines del instituto y con una propuesta de lege ferenda que aborda dos cuestiones: por un lado, la necesidad de modular la incidencia de las prestaciones obtenidas a través de los sistemas de previsión en el copago que habrá que satisfacer en el acceso a determinadas prestaciones públicas.

Por otro lado, CARLOS DE PABLO apunta a lo largo del texto un problema adicional. El sistema, tal y como está configurado, puede resultar beneficioso para aquellas familias que cuenten con recursos suficientes para poder destinarlos a la protección de un miembro con discapacidad. Sin embargo, poco uso de estos planes y de sus beneficios fiscales van a poder hacer las familias que cuenten con recursos exiguos, las cuales difícilmente podrán aportar cifras siquiera cercanas al tope que vimos. En definitiva, esto supone que el Estado financia en forma desigual, a través de reducciones y exenciones, situaciones idénticas, y lo hace atendiendo a la capacidad económica de las familias. Para evitar lo anterior y fomentar de forma decidida la protección de las personas con discapacidad se propone un nuevo modelo, a semejanza del que existe ya en Alemania, con dos ideas básicas: excluir la protección del ámbito del IRPF de los aportantes y sustituirla por aportaciones directas del Estado a los planes de pensiones del régimen especial. No es el momento de entrar en detalles, pero como nos expone el autor, este modelo pondría coto a la regresividad del sistema actual, ampliaría la protección pública de las personas con discapacidad y, de cara a la sociedad, dotaría al problema de una necesaria visibilidad.

Es esta una pincelada brevísima sobre una obra que trata a fondo un tema complejo pero que, no obstante, permite al lector desenvolverse fácilmente a través de la regulación financiera y fiscal de los planes de pensiones en favor de personas con discapacidad e identificar las patologías que sufre la regulación, para cada una de las cuales se encontrará una propuesta de solución. 